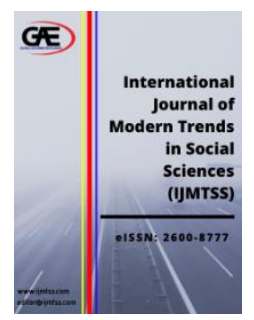

\author{
INTERNATIONAL JOURNAL OF \\ MODERN TRENDS IN \\ SOCIAL SCIENCES \\ (IJMTSS) \\ www.ijmtss.com
}

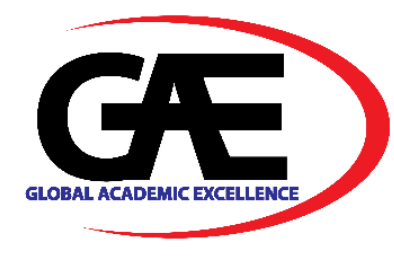

\title{
FACTORS INFLUENCING WORK ENGAGEMENT AMONG CANCER SURVIVORS IN MALAYSIA
}

\author{
Siti Nur Syuhada Musa*1, Siti Raba'ah Hamzah², Soaib Asimiran ${ }^{3}$, Zulaiha Muda ${ }^{4}$ \\ 1 Faculty of Educational Studies, Universiti Putra Malaysia (UPM), Malaysia \\ Email: Sn.syuhadamusa27@gmail.com \\ 2 Faculty of Educational Studies, Universiti Putra Malaysia (UPM), Malaysia \\ Email: srh@upm.edu.my \\ 3 Faculty of Educational Studies, Universiti Putra Malaysia (UPM), Malaysia, \\ Email: soaib@upm.edu.my \\ $4 \quad$ Paediatric Institute Hospital Kuala Lumpur, Malaysia \\ Email: mudazulaiha@gmail.com \\ Corresponding Author
}

\section{Article Info:}

\section{Article history:}

Received date: 17.01.2021

Revised date: 20.01.2021

Accepted date: 27.01.2021

Published date: 03.03.2021

\section{To cite this document:}

Musa, S. N. S., Hamzah, S. R., Asimiran, S., \& Muda, Z. (2021). Factors Influencing Work Engagement Among Cancer Survivors In Malaysia. International Journal of Modern Trends in Social Sciences, 4 (15), 43-53.

DOI: $10.35631 / \mathrm{IJMTSS} .415004$

This work is licensed under $\underline{\text { CC BY } 4.0}$

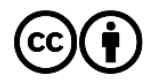

Abstract:

This study investigated the antecedents of work engagement of Malaysian employees who were cancer survivors. Work engagement refers to a positive, fulfilling, work-related state of mind characterizing employees who work hard and persist despite difficulties. Employees with high levels of work engagement are deeply involved in what they do and are happily absorbed in their work. This study was aimed to examine the individual and work environment-related factors that influence work engagement. A quantitative research paradigm was adopted, with a cross-sectional design using data collected from cancer survivors registered at the Hospital Kuala Lumpur. The 270 participants in this study were randomly selected by inclusive criteria sampling. A validated instrument was tested in a pilot study. Partial Least Square-Structural Equation Model (PLS-SEM) was used to test the direct effects of work engagement. It was found that the level of all the tested variables (work engagement, employee resilience, social support, and quality of working life) among the participants were high. This study highlights the importance of resilience and social support in improving work engagement among cancer survivors in Malaysia.

\section{Keywords:}

Work Engagement, Employee Resilience, Workplace Social Support, Quality Of Working Life, Cancer Survivors 


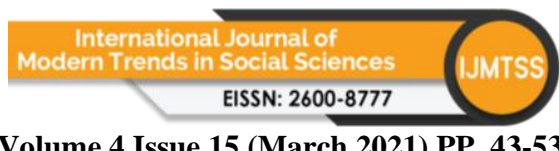

Volume 4 Issue 15 (March 2021) PP. 43-53 DOI 10.35631/IJMTSS.415004

\section{Introduction}

Cancer is a major morbidity and mortality concern in Malaysia. There are increase number of new cancer cases from 103,507 to 115,238 in the 2012-2016 period, with $44.7 \%$ being males and 55.3\% females (National Cancer Registry for 2012-2016). Cancer led to a tremendous economic burden on patients, their families and the societies. Apart from financial loss, cancer has important psychosocial effects, including work-related issues, on patients and their families (De Souza et al., 2017). Employment is important for the individual's wellbeing and is needed for economic, socializing and accomplishment reasons, as well as its contribution to the economy. Unfortunately, withdrawal from work participation is often associated with cancer survivors (Chow et al., 2015). Improvements in early detection and effective treatments of cancer have led to a high survival rate and, indeed, the rate of cancer survival has been increasing in Malaysia in recent times. The first population-based cancer survival study was reported by the National Cancer Registry Department, National Cancer Institute in 2018. The study reported 15 types of cancer with a five-year relative survival (RS) in Malaysia. The survival rate was higher in women and younger patients aged 15 - 44 years who encompassed $21 \%$ of the sample. The increasing number of cancer survivors in the workforce warrants immediate intervention by organizations to boost work engagement of these employees. As the population of cancer survivors is growing, it is important to understand the long-term effects of cancer and treatment of survivors at the workplace.

Many studies focus on work limitation for cancer survivors (Mehnert, de Boer \& Feurstein, 2013). Unfortunately, such a research focus might spark misconceptions of employers towards cancer survivors' ability at the workplace as well as cast negative perceptions of the impact of cancer treatments and about cancer in relation to work. There were also reports of decreased employment quality, as evidenced by decreased job satisfaction, increased turnover intention, decrease presenteeism, decreased job performance, and reduced in organizational commitment (Gonzalez et al., 2018). It is not surprising, therefore, that cancer survivors have to deal with negative perceptions of their ability and contribution to their organizations. Little is known about the cancer survivor's 'well-being, engagement, their daily activities, and their work abilities at the work place' (Hakanen \& Lindbohm, 2008).

To date, not many studies have been conducted on work engagement of cancer survivors. Are cancer survivors less engaged at work? This question leads to the research gap that this study hopes to fill by investigating the level of work engagement and the antecedents of work engagement among cancer survivors in Malaysia, as well as the role of workplace spirituality.

\section{Work Engagement}

Work engagement has been conceptualized in many ways, giving rise to numerous definitions, theories, and measurement instruments, as well as indecisiveness about the construct (Saks \& Gruman, 2014). In the context of work engagement, environmental factors include workplace social support and quality of working life. With regard to the present study, it was presumed that cancer survivors would have higher work engagement if they received support at the workplace; they would also strive to have efficacy if they knew they were supported and appreciated by their supervisor and co-workers. Also, other environmental factors in this study included quality of working life which could lead to behavioral aspirations or positive outcome expectations such as work engagement. Employees are found to be more engaged at work if they have better quality working life (Geisler et al., 2019). 


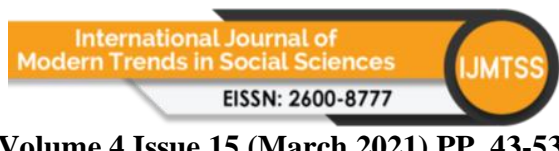

Volume 4 Issue 15 (March 2021) PP. 43-53 DOI 10.35631/IJMTSS.415004

\section{Employee Resilience and Work Engagement}

There is strong empirical evidence of employee resilience as one of the most important personal resources and antecedents for work engagement. Past research reveals that highly resilient individuals show they can cope better and adapt to adversity such as stress at workplace (Malik $\&$ Garg, 2020). Specifically, when employees display positive emotions, it triggers an 'upwardspiral' of psychological resources which stimulate resilience, which in turn, fosters work engagement. In line with Wang, $\mathrm{Li}$ and $\mathrm{Li}$ (2017), they reported that resilient employees faced adversity, they could successfully cope, adapt, and recover, thus experiencing positive emotions, which in turn contributed to enhancing work engagement. Next, Dai, Zhuang, and Huan (2019) demonstrated that resilience of travel agency employees was the essential trait that diminished their intention to leave the organization and enhance their work engagement. Hence, the higher the employees' resilience, the increased work engagement is. This leads to the first hypothesis:

H1: Employee resilience is positively associated with work engagement of cancer survivors.

\section{Social Support and Work Engagement}

Research on the influence of workplace social support has focused on assessing the influence of support received from various sources, namely supervisors and colleagues, to foster work engagement. According to Schaufeli and Bakker (2004), supervisory support is a critical resource that can be contributory in ensuring the successful accomplishment of work goals and help buffer stress associated with high job demands, thus leading to higher work engagement. For example, Kiema-Junes et al. (2020) reported that high social support at work namely supervisory support and collegial support was associated with higher total work engagement in Northern Finland. In another related study on the Asian diaspora, Nasurdin et al. (2018) revealed that peer support not only made it easier for employees to achieve their work goals but it also provided them with emotional support, particularly in times of stress, which in turn, motivated them to become more engaged with their work among staff nurses in Peninsular Malaysia. As indicated by previous studies, workplace social support gives rise to mutually beneficial actions, resulting in good relationships with superior and co-workers. Based on the discussion thus far regarding the important role of workplace social support in predicting work engagement, the following hypothesis is stated:

H2: Workplace social support significantly influences work engagement of cancer survivors.

\section{Quality of working life and work Engagement}

Over the years, a vast amount of research has convincingly enunciated the eminent role of quality of working life (QWL) in predicting work engagement. According Toscano-del Cairo et al. (2020) who opined from a South American perspective, the organization's effort to improve QWL yielded positive effects on the levels of engagement among employees of a higher education institution in Colombia. Together with job satisfaction, autonomy, work relations and continuing education, QWL is an important variable that influences work engagement (Geldenhuy, Laba, \& Venter, 2015). Thus, it is likely that employees with adequate benefits from their organization are more likely to be fully committed to their work. Furthermore, such employees would have high work engagement as they feel that they have been treated fairly and with dignity and respect. Markedly, the quality of working life is seen to foster work engagement. Consistent with the existing literature aforementioned, this is indeed another interesting avenue to explore, especially from the cancer survivors' perspective. 
Having discussed the important role of quality of working life in predicting work engagement, the following hypothesis is developed:

H3: Quality of working life significantly influences work engagement of cancer survivors.

\section{Conceptual Framework}

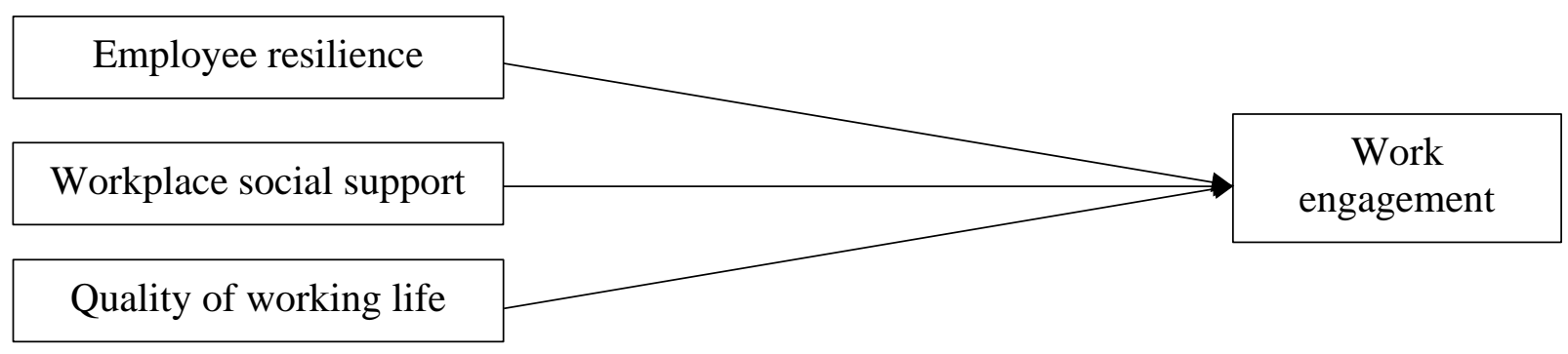

Figure 1: Research Framework

\section{Methodology}

A cross-sectional study design was conducted to determine the individual and work environment-related factors which influence work engagement among cancer survivors in Malaysia. The protocol of this study was approved by the Medical Ethics Committee (MREC), Ministry of Health, Malaysia and National Medical Research Registry (NMRR18-85-40225IIR). Employed cancer survivors were identified with the assistance of hospital staff. Present study was conducted in Paediatric Institute Hospital Kuala Lumpur which is the centre of excellence and national referral centre in all areas of paediatric services, advocating and promoting child health, providing and supporting training and research pertaining to child health. Furthermore, the Pediatric Institute in Hospital Kuala Lumpur as a prime site whereby it is known as a primary treatment centre for childhood cancer in Malaysia, and the patients have come from all over Malaysia. Moreover, Hospital Kuala Lumpur is now the largest hospital under the Ministry of Health of Malaysia and is considered to be the one of the biggest in Asia. Data collection was based on the list of children aged from newborn to 18 years who diagnosed with cancer and still on treatment or follow up in Paediatric Institute Hospital Kuala Lumpur in the period from 2015 to 2019 . The respondents in this study were selected using a systematic sampling from a list of all 1,192 eligible cancer survivors who had registered for follow-up sessions within a year. For the sample size, the precision was set at $5 \%$ and confidence interval at 95\% (Cohen, 2013), and the sample size were 285 cancer survivors.

\section{Measures}

This study utilized the Utrecht Work Engagement Scale (UWES-17) scale developed by Schaufeli et al. (2002) that uses a seven-point response format ranging from 0 (never) to 6 (every day). The composite reliability (CR) for work engagement was 0.937 , as shown in Table 2. Employee resilience was measured using the Näswall, Kuntz and Malinen, (2015) Employee Resilience Scale (EmpRes). The complete measure consisted of 12 items and was measured using a seven-point Likert scale ranging from 1 (never) to 7 (almost); CR for this study was 0.921. Workplace social support was measured using by Smith et al. (2013). Each item in this construct was measured using a five-point Likert scale ranging from 1 (strongly disagree) to 5 (strongly agree). The CR for this study was 0.884 . Quality of working life was measured using the Quality of Working Life Questionnaire for Cancer Survivors developed by de Jong et al. 
(2016) that contained 23 items scored on a five-point Likert scale ranging from 1 (strongly disagree) to 5 (strongly agree). The CR for this study was 0.947 . The questionnaire used in this study was based on a well-established instrument originally in English. Back to back translation procedures were applied to achieve semantic equivalence.

\section{Findings}

\section{Demographic Profile}

A total of 270 cancer survivors aged 18 to 40 years (mean 25.41) participated in this study. Participation of female cancer survivors was slightly higher at $51.5 \%$ than males (48.5\%). Most of them were Malays (68.5\%), followed by Chinese $(22.6 \%)$ and Indians $(7.0 \%)$. The respondents had different levels of educational qualifications: Master's degree $(1.5 \%)$, Bachelor's degree (27.8\%), Diploma (30.7\%), Higher Education Certificate of Malaysia (4.4\%), Malaysian Certificate of Education (31.1\%) and Certificate of Lower Education $(4.1 \%)$. With regard to marital status, $75.2 \%$ were single, $24.1 \%$ married, and $0.7 \%$ widowed. The demographic profile on work status showed that the majority of cancer survivors had permanent jobs (45.9\%), while $20.4 \%$ had temporary employment; $25.6 \%$ were self-employed, and $8.1 \%$ were part-time workers. The mean reported gross monthly income was between RM1001 and RM5000. In addition, the number of cancer diagnoses showed that $89.6 \%$ of the respondents had been diagnosed only once, $10.4 \%$ had been diagnosed more than once. The most common cancers were leukaemia (52.2\%), Hodgkin lymphoma (10.7\%), Wilms' tumour (5.9\%), Ependymoma (5.9\%), ovarian cancer (3.7\%). The demographic profiles of the respondents are shown in Table 1.

Table 1: Demographic Profiles of the Respondents $(n=270)$

\begin{tabular}{llll}
\hline Demographics & Category & Frequency & Percentage \\
\hline Gender & Male & 131 & 48.5 \\
Ethnicity & Female & 139 & 51.5 \\
& Malay & 185 & 68.5 \\
& Chinese & 61 & 22.6 \\
Indian & 19 & 7.0 \\
& Others & 5 & 1.9 \\
& Islam & 187 & 69.3 \\
& Buddhism & 52 & 19.3 \\
Marital status & Hinduism & 18 & 6.7 \\
& Christianity & 12 & 4.4 \\
& Others & 1 & 0.4 \\
Level of education & Single & 203 & 75.2 \\
& Married & 65 & 24.1 \\
& Widowed & 2 & 0.7 \\
& Master's degree & 4 & 1.5 \\
& Bachelor's degree & 75 & 27.8 \\
& Diploma & 83 & 30.7 \\
& Higher School Certificate & 12 & 4.4 \\
& Malaysian Certificate of & 84 & 31.1 \\
\hline
\end{tabular}


Work status

Types of cancer

Frequency of cancer diagnosis

Lower Certificate of Education

11

4.1

Permanent

124

55

Temporary

Self-employed

Part time

Leukemia

Breast cancer

Ovarian cancer

Hodgkin lymphoma

Testicular cancer

Papillary thyroid cancer

Nasopharyngeal cancer

Ependymoma

Yolk sac tumour

Wilms' tumour

Ewing's sarcoma

Langerhans Cell histiocytosis

Left Orbital RMS

Germinoma

Lung cancer

Brain cancer

Skin cancer

Pancreatic cancer

Embryonal rhabdomyosarcoma

Bladder cancer

Hepatoblasma

Neuroblastoma cancer

Medulloblastoma

69

22

141

1

10

29

5

1

1

16

7

16

9

2

2

2

3

5

2

1

1

1

7

6

6

242 >once

28

$<$ RM3,000

RM5,001-RM10,000

14

Age

18-20

59

97

21-25

61

26-30

30

31-35

36-40

23
89.6

5.2

21.9

35.9

45.9

20.4

25.6

8.1

52.2

0.4

3.7

10.7

1.9

0.4

0.4

5.9

0.7

0.7

07

1.1

1.9

0.7

0.4

0.4

0.4

2.6

1.5

2.2

10.4

22.6

11.1

8.5

Mean $($ Age $)=25.41 ;$ Standard deviation $=5.682$ 


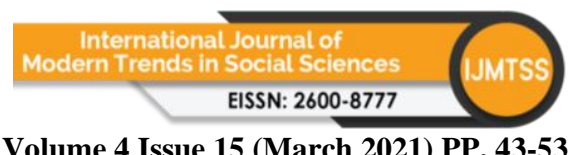

Volume 4 Issue 15 (March 2021) PP. 43-53 DOI 10.35631/IJMTSS.415004

\section{Data Analysis}

The partial least square structural equation modelling has experienced widespread recognition in recent times. Since the study hypotheses were directional, the application of variance-based structural equation modelling (e.g. PLS-SEM) was a preferred method for examining relationships in exploratory research. Hence, we used Smart PLS 3.0 software (Hair et al., 2012) for the data analysis. Two stages approach was applied in the PLS-SEM analysis. Reflective measurement on the outer model of the study and the structural model for the inner model to hypothesized the relationship.

\section{Assessment of the measurement model}

A measurement of the outer model's reliability and validity can be examined in terms of internal consistency, convergent validity, and discriminant validity. The internal consistency was assessed using composite reliability $(\mathrm{CR})$ values. A measurement model has satisfactory internal consistency reliability when the CR of each variable exceeds the threshold value of 0.7 (Hair, Ringle \& Sarstedt, 2013). Table 2 shows that the CR of each variable for this study ranged from 0.88 to 0.94 , all above the recommended threshold. The results indicated that the items used to represent the variables had satisfactory internal consistency reliability.

Next, the convergent validity of the outer model was examined for indicator reliability and average variance extracted (AVE). Fornell and Larcker (1981) suggest that a construct's convergent validity is still adequate if it has AVE less than 0.50, but CR above 0.60. As shown in Table 2, AVE values for work engagement, employee resilience and workplace social support were above 0.5 , however, the AVE value of QWL was below 0.50 , but since the CR value was above 0.60 , the construct thus had sufficient convergent validity (Table 2).

Table 2: Evaluation of Measurement Model

\begin{tabular}{llllll}
\hline Construct & Loading & AVE & CR & Mean & SD \\
\hline Work Engagement & 0.730 & 0.535 & 0.937 & 5.043 & .752 \\
Employee Resilience & 0.791 & 0.626 & 0.921 & 6.069 & .865 \\
Workplace Social Support & 0.773 & 0.608 & 0.884 & 4.116 & .562 \\
Quality of Working Life & 0.667 & 0.454 & 0.947 & 4.096 & .526 \\
\hline
\end{tabular}

Discriminant validity, on the other hand, evaluates the extent to which a construct is truly distinct from other constructs in the model, and thus seizes a single unique phenomenon (Hair et al., 2017). Heterotrait-monotrait ratio of correlations (HTMT) was utilized in this study to assess the measurement model's discriminant validity. In this case, as can be seen in Table 3, all the HTMT values are lower than the conservative threshold value of 0.85 . Discriminant validity was therefore established between all the construct pairs and distinctively different from one another.

Table 3: Discriminant validity assessment for the reflective variables (HTMT criterion)

\begin{tabular}{lcccc}
\hline & QWL & Resilience & Social Support & Work Engagement \\
\hline QWL & - & & & \\
Resilience & 0.747 & - & & \\
Social Support & 0.731 & 0.835 & - & - \\
Work Engagement & 0.180 & 0.108 & 0.158 & \\
\hline
\end{tabular}




\section{Structural Model Assessment}

The analyses of the hypothesis began with the structural model. In this study, the validity of the structural model was examined using the assessment of collinearity, significance, and the relevance of the structural model path coefficients, coefficient of determination $\left(\mathrm{R}^{2}\right)$, and predictive relevance $\left(\mathrm{Q}^{2}\right)$. First, collinearity statistics were measured using variance inflation factor (VIF) to evaluating multicollinearity. Table 4 shows that all VIF values were less than the threshold value of 5, indicating that collinearity among the exogenous constructs of the structural model was not at critical levels (Hair et al., 2017). Table 4 also shows the results for $\mathrm{Q}^{2}$ value for employee resilience (0.55), quality of working life $(0.41)$, workplace social support (0.41), work engagement (0.42) respectively. The satisfactory values of predictive relevance for the dependent variable of work engagement demonstrated the large predictive validity of the work engagement model.

Table 4: Validity of Structural Model (VIF, $\left.\mathbf{R}^{2}, \mathbf{Q}^{2}\right)$

\begin{tabular}{|c|c|c|c|c|c|c|c|}
\hline & \multirow{2}{*}{$\begin{array}{l}\text { VIF } \\
\text { WE }\end{array}$} & \multicolumn{3}{|c|}{$\mathbf{R}^{2}$ Value } & \multicolumn{3}{|c|}{$Q^{2}$ values } \\
\hline & & $\mathbf{R}^{2}$ & $\begin{array}{c}\text { Adjusted } \\
\mathbf{R}^{2}\end{array}$ & $\begin{array}{l}\text { Effect } \\
\text { size }\end{array}$ & SSO & SSE & $\begin{array}{c}Q^{2}(=1- \\
\text { SSE/SSO })\end{array}$ \\
\hline $\begin{array}{l}\text { Work } \\
\text { Engagement } \\
\text { (WE) }\end{array}$ & & 0.561 & 0.555 & Moderate & 536.366 & 307.566 & 0.427 \\
\hline Resilience & 2.509 & & & & 282.04 & 126.28 & 0.552 \\
\hline Social Support & 2.203 & & & & 194.05 & 113.184 & 0.417 \\
\hline $\begin{array}{l}\text { Quality Work } \\
\text { Life }\end{array}$ & 1.016 & & & & 903.612 & 531.878 & 0.411 \\
\hline
\end{tabular}

Next, the level and significance of the path coefficients were examined using a bootstrapping procedure with 5,000 bootstrap samples in Table 5. The results in support of H1 $(\beta=0.329, \mathrm{t}$ $=3.325)$ indicated that employee resilience had an influence on work engagement. Next, social support also had considerable influence on work engagement $(\beta=0.243, \mathrm{t}=3.399)$. Thus, $\mathrm{H} 2$ was supported. $\mathrm{H} 3$ focused on the influence of quality of working life on work engagement. However, the results $(\beta=0.034, t=0.621)$ suggested that the relationship was not significant. Thus, H3 was not supported.

Table 5: Hypothesis testing of structural model

\begin{tabular}{lccccc}
\hline Hypothesis & $\begin{array}{c}\text { Path } \\
\text { Coefficient }\end{array}$ & $\begin{array}{c}\text { Std. } \\
\text { Error }\end{array}$ & t value & p value & Decision \\
\hline $\mathrm{H} 1: \mathrm{ER} \rightarrow$ WE & 0.329 & 0.099 & $3.325^{* *}$ & 0.001 & Accepted \\
$\mathrm{H} 2: \mathrm{SS} \rightarrow$ WE & 0.243 & 0.071 & $3.399^{* *}$ & 0.001 & Accepted \\
$\mathrm{H} 3: \mathrm{QWL} \rightarrow$ WE & 0.034 & 0.056 & 0.621 & 0.535 & Rejected \\
\hline
\end{tabular}

Note: $\mathrm{t}$-value greater than 1.645 at $* \mathrm{p}<0.05$, $\mathrm{t}$-value greater than 2.33 at $* * \mathrm{p}<0.01$

$\mathrm{WE}=$ Work Engagement; ER= Employee Resilience; $\mathrm{SS}=$ Social Support; QWL= Quality of Working Life

\section{Discussion}

The main purpose of this study was to investigate the antecedents of work engagement, with special focus on the mediating role of workplace spirituality of cancer survivors. The cancer survivors in this study reported having high levels of work engagement. Thus, this study 


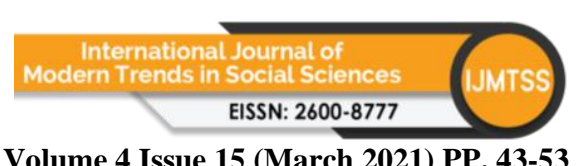

Volume 4 Issue 15 (March 2021) PP. 43-53

DOI 10.35631/IJMTSS.415004

concluded that cancer survivors were able to work and function as well as other employees who had not been stricken with cancer. The finding of this study thus, broadens the understanding of the researchers and practitioners by offering the empirical evidence of the study results. First, a direct correlation existed between employee resilience and work engagement $(0.325, \mathrm{p}<0.001)$. Resilience enhanced the cancer survivors' work engagement. This finding is well supported by Malik \& Garg (2020) which state that cultivating employee resilience might aid a pathway to fostering engaged employees, wherein the employees not only employ their resources to tackle new challenges but also find new ways to deal with demanding situations at the workplace.

The testing of the second hypothesis $(\mathrm{H} 2)$ resulted in a positive correlation between workplace social support and work engagement $(0.399, \mathrm{p}<0.001)$. The finding was similar to Wolter et al. (2019) whose study indicated that job resources like social support were capable of promoting work engagement internal and externally. Concurrently, Kiema-Junes et al. (2020) agreed that workplace social support influenced employee's work engagement. Hence, the present study concluded that the more the support received from the supervisor and co-worker, the more likely the cancer survivors will be engaged at work. Next, no significant relationship was found between QWL and work engagement; thus, H3 was not accepted. In this study, cancer survivors were engaged at the workplace without depending too much on the quality of working life. Next, the fourth hypothesis revealed a significant positive relationship between workplace spirituality and work engagement $(3.885, \mathrm{p}<0.000)$. Roof $(2015)$ had similar findings regarding the relation between workplace spirituality and work engagement. Employees will be engaged when they are allowed to conduct themselves at the spiritual level in their workplace.

\section{Implications of Study}

This study has a number of theoretical and practical implications for HRD. Firstly, the findings of the study contribute to a better understanding of the concept of work engagement of employees who are cancer survivors in Malaysia. With a paucity of research on the influence of employee resilience, workplace social support on workplace engagement of cancer survivors in Malaysia, this study thus offers significant implications for HRD practitioners to develop an arsenal of approaches by which to boost employee resilience and workplace social support to enhance work engagement.

\section{Acknowledgement}

The authors are thankful to the Ministry of Health for the Ethical Approval granted. This study was funded by the Universiti Putra Malaysia (9597500), Ministry of Higher Education Malaysia (2018-2020).

\section{References}

Chow, S. L., Loh, S. Y., \& Su, T. T. (2015). Perceived Barriers and Facilitators for Return to Work Among Colorectal Cancer Survivors: Malaysian Healthcare Professionals Experience-A Qualitative Inquiry. Journal of UOEH,37(2), 127-138. doi.org/10.7888/juoeh.37.127

Cohen, J. (2013). Statistical power analysis for the behavioral sciences. New York: Academic press.

Dai, Y. D., Zhuang, W. L., \& Huan, T. C. (2019). Engage or quit? The moderating role of abusive supervision between resilience, intention to leave and work engagement. Tourism Management, 70, 69-77. doi.org/10.1016/j.tourman.2018.07.014 


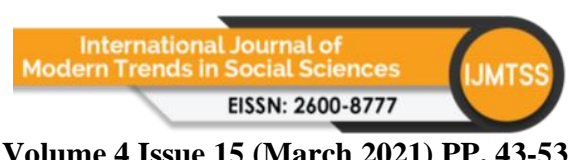

Volume 4 Issue 15 (March 2021) PP. 43-53

DOI 10.35631/IJMTSS.415004

de Jong, M., Tamminga, S.J., de Boer, A.G. and Frings-Dresen, M.H. (2016). "Quality of working life of cancer survivors: Development of a cancer-specific questionnaire”, Journal of Cancer Survivorship, 10(2), 394-405. doi.org/10.1007/s11764-015-0485-4

De Souza, J. A., Yap, B. J., Wroblewski, K., Blinder, V., Araújo, F. S., Hlubocky, F. J., ... \& Daugherty, C. K. (2017). Measuring financial toxicity as a clinically relevant patientreported outcome: the validation of the COmprehensive Score for financial Toxicity (COST). Cancer, 123(3), 476-484. doi.org/10.1002/cncr.30369

Fornell, Claes, \& Larcker, David F. (1981). Evaluating structural equation models with unobservable variables and measurement error. Journal of Marketing Research, 18(1), 39-50. doi.org/10.2307/3151312

Geldenhuys, M., Laba, K., \& Venter, C. M. (2014). Meaningful work, work engagement and organisational commitment. SA Journal of Industrial Psychology,40(1), 01-10. doi.org/10.4102/sajip.v40i1.1098

Geisler, M., Berthelsen, H., \& Muhonen, T. (2019). Retaining social workers: The role of quality of work and psychosocial safety climate for work engagement, job satisfaction, and organizational commitment. Human Service Organizations: Management, Leadership \& Governance, 43(1), 1-15. doi.org/10.1080/23303131.2019.1569574

Gonzalez, B. D., Grandner, M. A., Caminiti, C. B., \& Hui, S. K. A. (2018). Cancer survivors in the workplace: sleep disturbance mediates the impact of cancer on healthcare expenditures and work absenteeism. Supportive Care in Cancer, 26(12), 4049-4055. doi.org/10.1007/s00520-018-4272-4

Hair, J. F., Ringle, C. M., \& Sarstedt, M. (2013). Partial least squares structural equation modeling: Rigorous applications, better results and higher acceptance. Long Range Planning, 46(1-2), 1-12. https://ssrn.com/abstract=2233795

Hair, J. J. F., Hult, G. T. M., Ringle, C. M., Sarstedt, M. (2017). A Primer on Partial Least Squares Structural Equation Modelling (PLS-SEM) (2nd ed.). Thousand Oaks, CA: Sage.

Hakanen, J. J., \& Lindbohm, M. L. (2008). Work engagement among breast cancer survivors and the referents: the importance of optimism and social resources at work. Journal of Cancer Survivorship, 2(4), 283-295. doi.org/10.1007/s11764-008-0071-0

Kiema-Junes, H., Saarinen, A., Muukkonen, H., Väyrynen, S., Ala-Mursula, L., \& Hintsanen, M. (2020). Dimensions of social support in the experience of work engagement in middle age: A Northern Finland Birth Cohort 1966 Study. Scandinavian Journal of Psychology. 61(5), 679-689. doi.org/10.1111/sjop.12640

Malik, P., \& Garg, P. (2020). Learning organization and work engagement: The mediating role of employee resilience. The International Journal of Human Resource Management, 31(8), 1071-1094. doi.org/10.1080/09585192.2017.1396549

Mehnert, A., de Boer, A., \& Feuerstein, M. (2013). Employment challenges for cancer survivors. Cancer, 119(S11), 2151-2159. doi.org/10.1002/cncr.28067

Nasurdin, A. M., Ling, T. C., \& Khan, S. N. (2018). Linking Social Support, Work Engagement and Job Performance in Nursing. International Journal of Business \& Society, 19(2), 363-386.

National Cancer Registry Department, National Cancer Institute (2018), available at: http://nci.moh.gov.my/index.php/ms/main-menu-2/laporan

Näswall, K., Kuntz, J., and Malinen, S. (2015) Employee Resilience Scale (EmpRes): Technical Report. Resilient Organisations Research Report Christchurch, New Zealand. 2015/04. ISSN 1178-7279. 
Roof, R. A. (2015). The association of individual spirituality on employee engagement: The spirit at work. Journal of Business Ethics, 130(3), 585-599. doi.org/10.1007/s10551014-2246-0

Saks, A. M., \& Gruman, J. A. (2014). What do we really know about employee engagement?. Human Resource Development Quarterly, 25(2), 155-182. doi.org/10.1002/hrdq.21187

Schaufeli, W. B., \& Bakker, A. B. (2004). Job demands, job resources, and their relationship with burnout and engagement: A multi-sample study. Journal of Organizational Behavior: The International Journal of Industrial, Occupational and Organizational Psychology and Behavior, 25(3), 293-315. doi.org/10.1002/job.248

Schaufeli, W.B., Salanova, M., González-romá, V. et al. (2002). The Measurement of Engagement and Burnout: A Two Sample Confirmatory Factor Analytic Approach. Journal of Happiness Studies, 3, 71-92. doi.org/10.1023/A:1015630930326

Toscano-del Cairo, C.A., Vesga-Rodríguez, J.J. \& Avendaño-Prieto, B.L. (2020). Quality of life at work and its relationship with engagement. Acta Colombiana de Psicología, 23(1), 138-146. doi.org/10.14718/ACP.2020.23.1.7

Wolter, C., Santa Maria, A., Gusy, B., Lesener, T., Kleiber, D., \& Renneberg, B. (2019). Social support and work engagement in police work. Policing: An International Journal, 42(6) 1022-1037. doi.org/10.1108/PIJPSM-10-2018-0154 